\title{
Antimicrobial resistance in Canada: Update on activities of the Canadian Committee on Antibiotic Resistance
}

\author{
John Conly MD FRCPC for the Canadian Committee on Antibiotic Resistance
}

$\mathrm{T}$ he present article continues a series of updates on activities of the Canadian Committee on Antibiotic Resistance (CCAR). CCAR is a national organization formed to coordinate efforts to control the development and transmission of antibiotic resistance in Canada. CCAR will host a National Policy Conference on Antibiotic Resistance, to be held in Ottawa from October 5 to 7, 2002. The conference will provide information on the status of resistance in Canada, discuss public policy responses to the problem and develop a consensus on the formation of a National Action Plan. The conference is supported by educational grants from 3M Canada; Aventis Pharma Inc, Canada; Pharmacia Canada Inc; Pfizer Canada Inc; Bristol Myers-Squibb Canada, Inc; Bayer Inc, Canada; IMS Health Canada; and Health Canada. Health Canada has also agreed to provide $\$ 500,000$ over the next two years to continue to support CCAR's ongoing efforts.

In conjunction with the Canadian Pharmacists Association, CCAR is developing an information kit to be distributed to pharmacists across Canada in the fall of 2002. The kit will contain an introductory brochure, a guide for parents, a poster and a continuing education program for pharmacists. A qualitative evaluation component will be conducted following its distribution. For information, contact Barry Power at bpower@pharmacists.ca.

A Burden of Illness study commissioned by CCAR was completed recently. The results of the project, which was the first attempt to examine comprehensively the human and economic impact of drug-resistant infections in Canada, are available through the CCAR Web site $<$ www.ccar-ccra.org $>$. The study's final report provides a model for assessing the financial costs of antibiotic resistance, as well as qualitative information derived from interviews with patients and care providers on the personal and social impact of resistant infections. The report estimates that resistant infections add approximately $\$ 25$ to $\$ 40$ million annually in direct hospitalization costs to health care expenditures in Canada, an amount that could increase to $\$ 64$ to $\$ 102$ million/year if Canadian resistance rates reach American levels. In addition, if resistance rates rise to levels at which significant numbers of physicians shift to prescribing more expensive drugs, the annual cost of antibiotic prescriptions written could climb from about $\$ 600$ million (the current cost) to $\$ 1.8$ billion.

Following are updates on the activities of several CCAR affiliated organizations.

\section{HEALTH CANADA}

Division of Enteric, Foodborne and Waterborne Diseases Health Canada is coordinating the development of a Canada-wide pilot surveillance program for antimicrobialresistant enteric pathogens. This two-year program will test the feasibility of a representative and methodologically unified approach, modelled after initiatives in the United States and Europe, for monitoring trends in the development of resistance in Salmonella species from human, animal and food sources across Canada. The pilot program, scheduled to begin in September, is being developed and implemented in partnership with provincial public health laboratories, the National Laboratory for Enteric Pathogens (NLEP) and the Laboratory for Foodborne Zoonoses. The Division of Enteric, Foodborne and Waterborne Diseases is coordinating the human component of the program, in which a representative selection of isolates (in phase 1: nontyphoidal Salmonellae) will be identified by participating provincial laboratories and sent to the NLEP for resistance testing and phage typing. Human resistance data will be integrated with agrifood data to examine antimicrobial

Chairman, Canadian Committee on Antibiotic Resistance; University of Calgary, Calgary, Alberta

Correspondence: Dr John Conly, clo Canadian Committee on Antibiotic Resistance, 3806 West 33rd Avenue, Vancouver, British Columbia V6N 2H6. Telephone 604-263-4520, fax 604-263-7074, e-mail ccar@shaw.ca 
resistance along the food chain. In addition to the pilot program, several studies are underway or have recently been completed in the Division of Enteric, Foodborne and Waterborne Diseases: a multiprovincial Salmonella typhimurium casecontrol study, a national survey on enteric pathogens administered to all microbiology laboratories in Canada, and a study of resistance trends in Salmonella species and Shigella species using data received from five provinces. For information, contact Kathryn Doré at kathryn_dore@hc-sc.gc.ca.

\section{Laboratory for Foodborne Zoonoses}

The Laboratory for Foodborne Zoonoses, through its Antimicrobial Resistance Unit, has taken a lead role in the development of strategies to gather information on antimicrobial use and resistance in the agrifood and aquaculture sectors. The active surveillance component will incorporate data on Salmonella species and generic Esherichia coli obtained from healthy animals at slaughter, and on Salmonella species, E coli and Campylobacter species from retail meats. Veterinary clinical diagnostic isolates collected through passive surveillance systems will also be studied for susceptibility testing. These data will be integrated with data on human isolates of Salmonella species. In addition, Health Canada is working with an international group coordinated through the World Health Organization to standardize antimicrobial use monitoring in agriculture and aquaculture. For information, contact Rebecca Irwin at rebecca_irwin@hc-sc.gc.ca.

\section{Veterinary Drugs Directorate}

An Interdepartmental Antimicrobial Resistance Policy Committee was formed in January 2002 with a focus on human and nonhuman uses of antibiotics and other antibacterial agents. The policy committee comprises representatives of several federal government departments, including Health Canada, the Canadian Food Inspection Agency, Environment Canada and Fisheries and Oceans Canada. The Committee, in conjunction with an Interdepartmental Antimicrobial Resistance Science Committee, is responsible for developing risk management options based on the Science Committee's risk assessments and other considerations including social, cultural, political, environmental and economic impacts. The committee also will identify and prioritize science gaps and policy research needs related to antibiotic resistance in Canada. For information, contact Lateef Adewoye at lateef_adewoye@hc-sc.gc.ca.

\section{THE CANADIAN VETERINARY MEDICAL ASSOCIATION}

The Canadian Veterinary Medical Association (CVMA) recently completed the production and distribution of an information kit on the prudent use of antimicrobial drugs to all veterinarians in Canada. Since that time, the CVMA has focused on two strategy directions: representations to the federal government urging continued research and policy discussions at the national level, and the development of species-specific guidelines on the use of antimicrobial drugs. To date, guidelines have been adopted for cattle and swine, and the association is developing guidelines for poultry. The CVMA also maintains educational efforts for veterinarians; a continuing education module on the prudent use of antibiotics was included in the scientific program of the association's 2002 annual convention. For information, contact Suzanne Lavictoire at slavictoire@cvma-acmv.org.

\section{CANADIAN ANIMAL HEALTH INSTITUTE}

The Canadian Animal Health Institute (CAHI) is a trade association representing the manufacturers and distributors of animal medications in Canada. CAHI has developed an electronic database to support the prudent use of antimicrobials in animals and produces quality assurance programs. The database, which includes all licensed Canadian animal medications, is available to veterinarians and food animal producers. To further its food safety efforts, CAHI continues to work with government and industry partners to promote a Canadian regulatory process that is timely and responsive in its assessment of products while eliminating the use of unlicensed products in animals. For information, contact Jean Szkotnicki at jszk@cahi-icsa.ca.

\section{BRITISH COLUMBIA CENTRE FOR DISEASE CONTROL}

The British Columbia Centre for Disease Control (BCCDC) is working with the British Columbia chapter of the Canadian Association of Microbiologists to improve surveillance for resistant organisms. BCCDC is also collaborating with infectious diseases specialists at the University of British Columbia and with the British Columbia College of Pharmacists to evaluate trends in antimicrobial usage in the province and relate them to changes in susceptibility patterns of key microorganisms. A project focusing on clinically relevant pneumococcal disease as well as vancomycin-resistant enterococci and methicillin-resistant Staphylococcus aureus will be completed soon, and several publications are in preparation. Guidelines on the transfer between care institutions of individuals with resistant organisms have been developed by BCCDC's Infection Control Program and recently were broadly disseminated to practitioners. For information, contact David Patrick at david.patrick@bccdc.ca.

\section{ONTARIO MINISTRY OF HEALTH AND LONG-TERM CARE}

Last year. the Ontario Ministry of Health and Long-Term Care (MOHLTC) introduced significant changes to the province's reimbursement policy for anti-infective medications. The most significant change affected the quinolone antibiotics, some of which were listed previously as a general benefit and are now classified as limited use products to encourage more optimal utilization. While the macrolides continue to be listed as general benefit products, the ministry is concerned that potential increases in macrolide use may result in increased resistance to these agents. The 
MOHLTC has commissioned a retrospective study through the Ontario Optimal Program for Therapeutics of three targeted antimicrobials (azithromycin, clarithromycin and amoxicillin/clavulanic acid) identified as having a potential for misuse in the community. The study will assess the impact of use guidelines and reimbursement policy changes on prescribing patterns. For information, contact David Shum at david.shum@moh.gov.on.ca.

\section{MANITOBA ANTIBIOTIC RESISTANCE LABORATORY}

The Manitoba Antibiotic Resistance Laboratory (MARL) is a hospital/university sponsored research group of the Health Sciences Centre (Winnipeg) and the University of Manitoba. Recent and ongoing antibiotic resistance surveillance studies include: the Canadian Respiratory Organism Susceptibility Study on Streptococcus pneumoniae, Haemophilus influenzae, Moraxella catarrhalis and Streptococcus pyogenes; the North American Vancomycin Resistant Enterococcus Susceptibility Study; and the Canadian Antifungal Resistance Study, which assesses antifungal resistance in yeast and filamentous fungi. In addition, MARL has initiated the North America Urinary Tract Infection Collaborative Alliance study to assess resistance in outpatient and inpatient urinary tract pathogens in Canada and the United States. For information, contact George Zhanel at ggzhanel@pcs.mb.ca.

\section{TRIP II CLINICAL TRIAL}

To optimize the use of antibiotics in residents of long term care facilities, a group of Canadian and American investigators is conducting a cluster, randomized controlled trial of clinical algorithms in 22 nursing homes in Hamilton, Ontario and Boise, Idaho. The two-year trial aims to achieve a substantial reduction in antibiotic prescriptions. This is the first Canadian-led trial funded by the United States Agency for Healthcare Research and Quality through its Translating Research into Practice (TRIP) ini- tiative. For information, contact Mark Loeb at loebm@mcmaster.ca.

\section{MEROPENEM SURVEILLANCE STUDY}

The Meropenem Yearly Susceptibility Test Information Collection (MYSTIC) program is a longitudinal surveillance study of antimicrobial susceptibility. The program, initiated by AstraZeneca in 1997, collects Gram-positive and Gram-negative bacterial isolates from medical facilities where meropenem is available for use and examines their susceptibility to a range of antibiotics. Four Canadian facilities are among the 79 centres from 24 countries involved in the MYSTIC program. For information, contact Heather Cook at heather.cook@astrazeneca.com.

\section{"DO BUGS NEED DRUGS?"}

"Do Bugs Need Drugs?" is an Alberta-based awareness and information program that offers community and professional education on antibiotic resistance. Key messages explain the value of handwashing, the difference between bacterial and viral infections and the importance of using antibiotics wisely. A recently launched project targets children aged two to five years, and their caregivers and parents. Funded by a Health Innovation Grant from Alberta Health and Wellness, the project involves child care facilities in Edmonton and Calgary. For information, contact Edith Blondel-Hill at eblondel@cha.ab.ca,

Web site < www.do-bugsneeddrugs.org $>$.

CCAR members include health care professional organizations, not-for-profit industrial associations and government agencies. CCAR activities are funded primarily through a contract agreement with Health Canada as well as through educational grants from companies with an interest in antibiotic resistance. The Canadian Infectious Disease Society provides financial and administrative support.

For more information about CCAR, please contact Rick Walter, Executive Director, Canadian Committee on Antibiotic Resistance, 3806 West 33rd Avenue, Vancouver, British Columbia V6N 2H6. Telephone 604-263-4520, fax 604-2637074,e-mail ccar@shaw.ca, Web site <www.ccar-ccra.org>. 


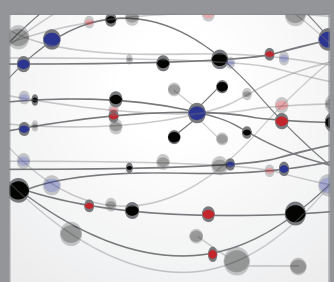

The Scientific World Journal
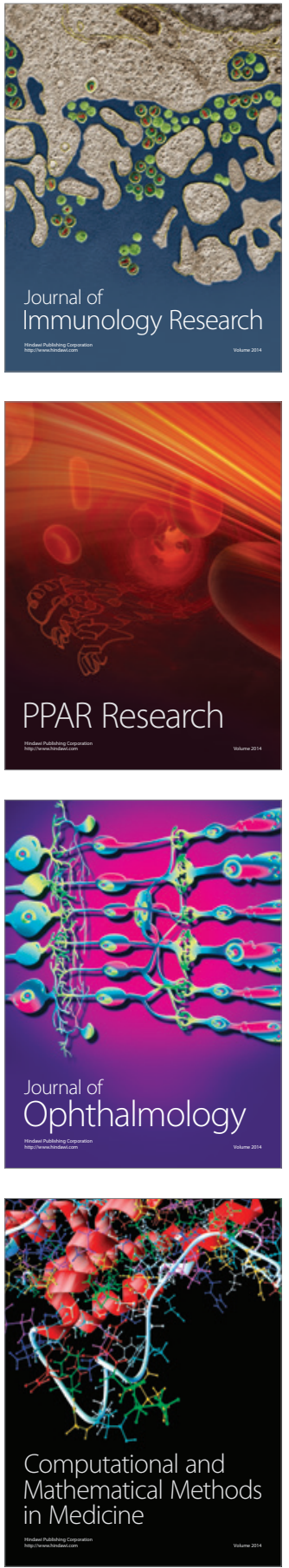

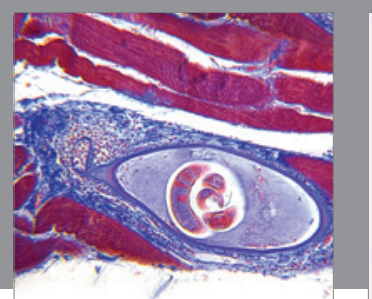

Gastroenterology Research and Practice

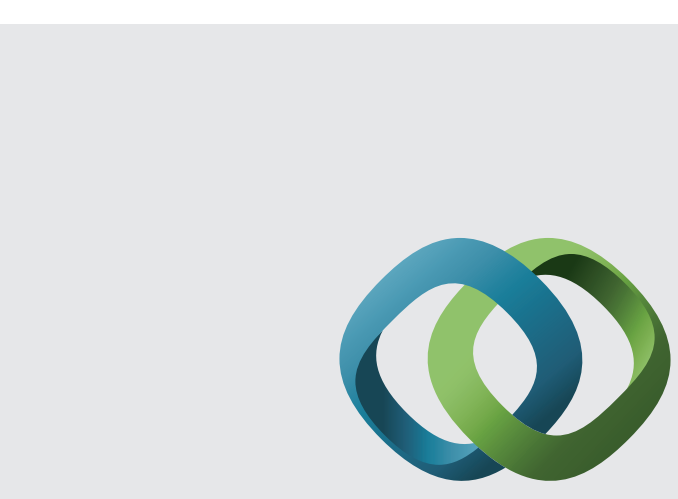

\section{Hindawi}

Submit your manuscripts at

http://www.hindawi.com
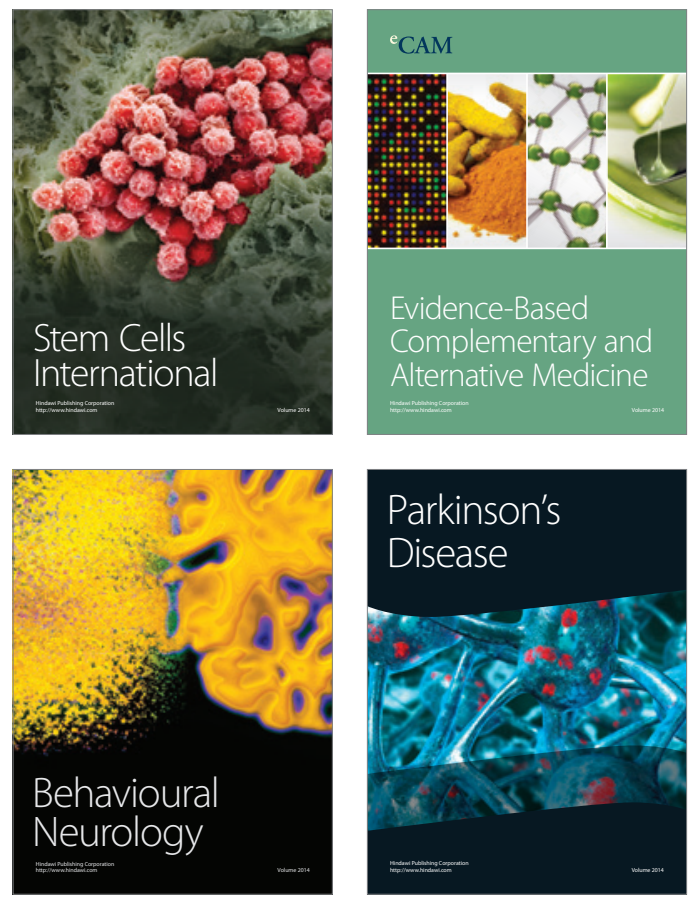
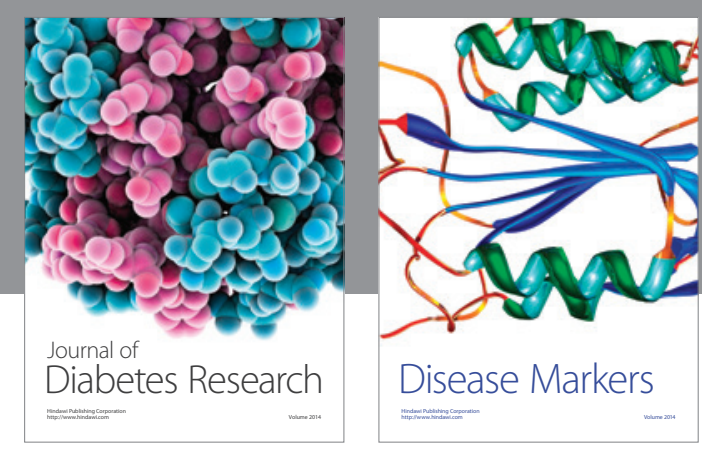

Disease Markers
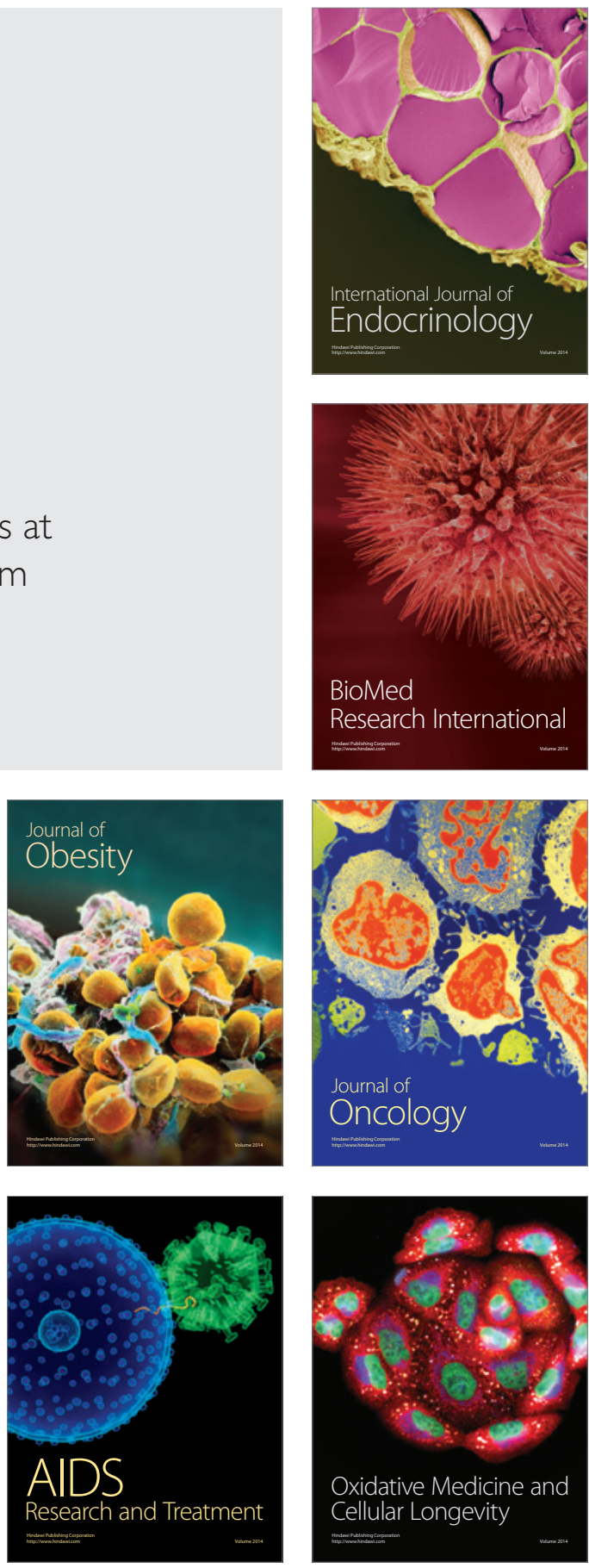